\title{
Cardiovascular risk evaluation and prevalence of silent myocardial ischemia in subjects with asymptomatic carotid artery disease
}

This article was published in the following Dove Press journal:

Vascular Health and Risk Management

3 March 20II

Number of times this article has been viewed

\section{Marco Matteo Ciccone \\ Artor Niccoli-Asabella ${ }^{2}$ \\ Pietro Scicchitano' \\ Michele Gesualdo' \\ Antonio Notaristefano ${ }^{2}$ \\ Domenico Chieppa' \\ Santa Carbonara' \\ Gabriella Ricci' \\ Marco Sassara' \\ Corinna Altini² \\ Giovanni Quistelli' \\ Mario Erminio Lepera' \\ Stefano Favale ${ }^{1}$ \\ Giuseppe Rubini \\ 'Cardiovascular Diseases Section, Department of Emergency and Organ Transplantation (DETO), ${ }^{2}$ Nuclear Medicine Unit, Department of Internal Medicine and of Public Medicine, University of Bari, Bari, Italy}

Correspondence: Marco Matteo Ciccone Piazza G. Cesare II - 70I242, Bari, Italy Tel +39 080-547879l

$\mathrm{Fax}+39$ 080-5478796

Email ciccone@cardio.uniba.it
Introduction: Silent ischemia is an asymptomatic form of myocardial ischemia, not associated with angina or anginal equivalent symptoms, which can be demonstrated by changes in ECG, left ventricular function, myocardial perfusion, and metabolism. The aim of this study was to evaluate the prevalence of silent myocardial ischemia in a group of patients with asymptomatic carotid stenosis.

Methods: A total of 37 patients with asymptomatic carotid plaques, without chest pain or dyspnea, was investigated. These patients were studied for age, sex, hypertension, diabetes, dyslipidemia, smoking, and family history of cardiac disease, and underwent technetium-99 m sestamibi myocardial stress-rest scintigraphy and echo-color Doppler examination of carotid arteries.

Results: A statistically significant relationship $(P=0.023)$ was shown between positive responders and negative responders to scintigraphy test when both were tested for degree of stenosis. This relationship is surprising in view of the small number of patients in our sample. Individuals who had a positive scintigraphy test had a mean stenosis degree of 35\% $\pm 7 \%$ compared with a mean of $44 \% \pm 13 \%$ for those with a negative test. Specificity of our detection was $81 \%$, with positive and negative predictive values of $60 \%$ and $63 \%$, respectively.

Conclusion: The present study confirms that carotid atherosclerosis is associated with coronary atherosclerosis and highlights the importance of screening for ischemic heart disease in patients with asymptomatic carotid plaques, considering eventually plaque morphology (symmetry, composition, eccentricity or concentricity of the plaque, etc) for patient stratification.

Keywords: asymptomatic carotid artery disease, silent myocardial ischemia, myocardial stress scintigraphy

\section{Introduction}

For many years angina pectoris has been considered the cardinal symptom of myocardial ischemia. Nevertheless, studies beginning in the 1980s have shown that asymptomatic ischemia is the most common manifestation of coronary heart disease (CHD). ${ }^{1,2}$ For example, many reports have documented that between $25 \%$ and $45 \%$ of patients with acute and chronic ischemic syndromes have evidence of myocardial ischemic episodes during daily activities, with minimal or no physical exercise, ${ }^{3,4}$ and greater than $75 \%$ of these are not associated with angina or anginal equivalent symptoms. ${ }^{4}$

Silent myocardial ischemia (SMI) is defined as the presence of objective findings suggestive of ischemia in the absence of chest pain or other anginal equivalent symptoms (dyspnea, arrhythmia). ${ }^{5}$ 
Objective evidence of myocardial ischemia may be:

- Exercise testing or ambulatory monitoring shows transient ST segment changes;

- Nuclear imaging studies demonstrate myocardial perfusion defects;

- Reversible regional wall motion abnormalities are provoked during stress or dobutamine echocardiography.

It has been estimated that in a population of male adults, the prevalence of SMI is $2 \%$ to $4 \%{ }^{6}$ but the percentage is higher in patients affected by stable angina and in postinfarction patients. ${ }^{7}$ Nevertheless, despite the fact that patients without clinical manifestations, but with positive results to the exercise test, have been reported to have a $27 \%$ higher incidence of acute coronary syndromes, ${ }^{8}$ the clinical relevance of SMI is still underestimated.

Although atherosclerosis is a pathological multifocal and multiregional process, a non-invasive evaluation by ultrasonography of unique regions like the carotid artery wall find great applicability in a more precise estimate of the overall progression of atherosclerosis and, consequentially, of cardiovascular risk profile. Based on the evident association between asymptomatic carotid stenosis and silent obstructive coronary artery disease, ${ }^{9-12}$ the aim of this study was to evaluate the prevalence of SMI in a group of patients with asymptomatic carotid artery plaques. The main methods utilized in this observational study were high definition vascular echotomography and technetium-99m sestamibi myocardial stress-rest scintigraphy.

\section{Methods}

\section{Study population}

Thirty-seven patients (25 males) with asymptomatic carotid plaques and free from chest pain or dyspnea, aged $66 \pm 8$ years, admitted to the Cardiology Unit, Emergency and Organ Transplant Department of Bari University General Hospital, were enrolled in the study.

All patients were carefully assessed for classic coronary risk factors: age, sex, essential hypertension, dyslipidemia, smoking, diabetes, a family history of cardiac disease (Table 1). Prior written informed consent was obtained to undertake technetium-99m sestamibi myocardial stress-rest scintigraphy and echo-color Doppler examination.

A hypertension state was defined as a systolic blood pressure of $>140 \mathrm{~mm} \mathrm{Hg}$ and/or diastolic blood pressure was $>90 \mathrm{~mm} \mathrm{Hg}$. In addition, in accordance with the NCEP ATP III, ${ }^{13}$ all patients had hypercholesterolemia, defined as total cholesterol $\geq 220 \mathrm{mg} / \mathrm{dL}$ or the use of lipid-lowering $\operatorname{drug}(\mathrm{s})$.
Table I Baseline demographic and clinical variables

\begin{tabular}{ll}
\hline No. patients & $\mathbf{N}=\mathbf{3 7}$ \\
\hline Age (years) & $66 \pm 8$ \\
Male sex (\%) & $25(68)$ \\
Family history (\%) & $17(46)$ \\
Hypertension (\%) & $19(5 \mathrm{I})$ \\
Diabetes (\%) & $8(22)$ \\
Dyslipidemia (\%) & $20(54)$ \\
Smoking (\%) & $10(27)$ \\
Stenosis (\%) & $0.4 \pm 0.12$ \\
Exercise test & \\
Positive (\%) & $10(27)$ \\
Doubt (\%) & $3(8)$ \\
Negative (\%) & $24(65)$ \\
ECG ST depression & \\
0 (\%) & $24(65)$ \\
0-I (\%) & $3(8)$ \\
$>$ I (\%) & $10(27)$ \\
Perfusion defect & $0.86 \pm 1.06$ \\
Site of stenosis & \\
Bilateral internal carotid (\%) & $1(3)$ \\
Left common carotid (\%) & $1(3)$ \\
Right internal carotid (\%) & $8(22)$ \\
Right common carotid (\%) & $3(8)$ \\
Bilateral common carotid (\%) & $3(8)$ \\
Left internal carotid (\%) & $13(35)$ \\
Left carotid bifurcation (\%) & $3(8)$ \\
Right carotid bifurcation (\%) & $5(14)$ \\
Degree of stenosis & \\
No stenosis (\%) & $0(0)$ \\
Mild stenosis (\%) & $16(43)$ \\
Moderate stenosis (\%) & $17(46)$ \\
High stenosis (\%) & $4(11)$ \\
Very high stenosis (\%) & $0(0)$ \\
\hline Note:Men vals sD on & \\
\hline
\end{tabular}

Note: Mean values \pm SD or number and percentage of patients.

Diabetes was defined as fasting blood sugar $\geq 126 \mathrm{mg} / \mathrm{dL}$, blood sugar during 75 g oral glucose tolerance test $\geq 200 \mathrm{mg} / \mathrm{dL}$, or the use of antidiabetes drug(s).

\section{Carotid ultrasound scanning}

All patients underwent a two-dimensional echo-color Doppler examination of carotid arteries bilaterally using a high-definition vascular echograph (Philips SONOS 5500 ultrasonographer, Bothell, WA) and a $7.5 \mathrm{MHz}$ highresolution probe.

Patients were placed in supine position with their neck in extension and rolled contralaterally by about $45^{\circ}$. The carotid arteries were examined in the long- and short-axis view. Each scan was made by the same investigator.

The Mannheim carotid intima-media thickness consensus (2004-2006) ${ }^{14}$ defined evaluation criteria of intima-media thickness (IMT) and atherosclerotic plaques. The presence of atherosclerotic plaques can be diagnosed by detection of an 
IMT $>1.3 \mathrm{~mm}$ or a focal structure emerging from the wall of at least $0.5 \mathrm{~mm}$ or $50 \%$ of the surrounding IMT value.

In our study the degree of carotid artery stenosis was graded as: 1) no stenosis; 2) mild: $1 \%$ to $39 \%$ stenosis; 3) moderate: $40 \%$ to $59 \%$ stenosis; 4) high-grade: $60 \%$ to $79 \%$ stenosis; 5 ) very high grade: $80 \%$ to $99 \%$ stenosis.

\section{Myocardial stress-rest scintigraphy}

Technetium-99m sestamibi myocardial perfusion stress-rest scintigraphy was performed in all patients.

The stress test was carried out on the bicycle ergometer e-Bike (GE Healthcare, West Milwaukee, WI), with patients in the sitting position, under continuous ECG monitoring (MAC5500, GE Healthcare, West Milwaukee, WI), progressively increasing the load by $25 \mathrm{~W}$ every 2 minutes, until exhaustion, symptoms, or $>1 \mathrm{~mm}$ ST segment depression developed. The stress test was considered positive for myocardial ischemia when the ECG showed an ST segment depression $>1 \mathrm{~mm}$ measured $80 \mathrm{msec}$ after the $\mathrm{J}$ point.

All patients received an intravenous dose of technetium$99 \mathrm{~m}$ sestamibi at peak physical stress (peak heart rate $>80 \%$ of the predicted value for age), 30 to 60 seconds before the end of exercise. After administration of the radiopharmaceutical the patients were give milk to drink (light fatty meal) to eliminate the drug from the gallbladder through the gastrointestinal tract, and to minimize interference.

One hour after the drug injection the patients underwent SPECT (single photon emission computed tomography) to acquire stress images.

The next day, 1 hour after the injection of the same technetium-99m sestamibi quantity, they underwent the rest test, so that the interval between resting and exercise studies was $>24$ hours.

Images were acquired using a large-field, dual-headed, Infinia gamma camera (GE Healthcare), equipped with a high resolution collimator. A semicircular orbit of $180^{\circ}$, from $45^{\circ}$ right anterior oblique to $45^{\circ}$ left posterior oblique, and with step detections every $3^{\circ}$, was carried out. Image reconstruction, display, and analysis were performed by standard software package using Xeleris Workstation (GE Healthcare). Filtered back projection was performed with a low-resolution Butterworth filter with a cut-off frequency of 0.5 cycles/pixel, order 5.0. No attenuation or scatter correction was applied. The left ventricle transaxial tomographic slices were reoriented into the short, horizontal, and vertical long-axis views according to current recommendations.

The following myocardial regions were evaluated: anterior, apical, septal, inferior, and lateral. The uptake in each of these regions was evaluated as normal, equivocal, mild defect, moderate defect, or severe defect (similar to the background uptake).

Analysis of the results revealed areas of myocardial infarction (MI) (a perfusion defect at rest and stress test) and myocardial ischemia (a perfusion defect only at the stress test).

\section{Statistical analyses}

Continuous variables were expressed as mean values \pm standard deviation, and frequencies as the number and percentage of patients. Categorical variables were compared between groups using the chi-squared or Fisher's exact test as appropriate. The other between-group comparisons were made by means of non-parametric Mann-Whitney $U$ test. $P$ values of $<0.05$ were considered statistically significant. The data were analyzed using the statistical software package Statistica version 6.1 (StatSoft Inc., Tulsa, OK).

\section{Results}

Table 1 gives the baseline demographic and clinical variables of the studied population, showing that all patients had a certain $(40 \% \pm 12 \%)$ degree of carotid stenosis (within mild, moderate, and high, according to our classification of plaques in the Methods section) although the exercise test was positive in at least 10 individuals (27\%).

Table 2 shows the results of scintigraphy, related to the degree of stenosis detected by echo-color Doppler. We compared scintigraphy data even against common cardiovascular risk factors. A statistically significant relationship $(P=0.023)$ was shown between positive responders and negative responders to scintigraphy test when both were tested for degree of stenosis. This relationship is surprising in view of the small number of patients in our sample. Individuals who had a positive scintigraphy test had a mean stenosis degree of $35 \% \pm 7 \%$ compared with a mean of $44 \% \pm 13 \%$ for those with a negative test.

Table 2 Baseline demographic and clinical variables by scintigraphy

\begin{tabular}{llll}
\hline No. patients & $\begin{array}{l}\text { Positive } \\
\mathbf{n = ~ 1 6}\end{array}$ & $\begin{array}{l}\text { Negative } \\
\mathbf{n = 2 ~ I ~}\end{array}$ & P value \\
\hline Age (years) & $66 \pm 8$ & $66 \pm 8$ & $0.5 \mathrm{I}$ \\
Male sex (\%) & I4 (88) & II (52) & 0.024 \\
Family history (\%) & $6(38)$ & II (52) & 0.37 \\
Hypertension (\%) & I0 (63) & $9(43)$ & 0.24 \\
Diabetes (\%) & I (6) & $7(33)$ & 0.10 \\
Dyslipidemia (\%) & $8(50)$ & I2 (57) & 0.67 \\
Smoking (\%) & $4(25)$ & $6(29)$ & 1.00 \\
Stenosis & $0.35 \pm 0.07$ & $0.44 \pm 0.13$ & 0.023 \\
\hline
\end{tabular}

Note: Mean values \pm SD or number and percentage of patients. 
Table $3 \mathrm{a}$ and $3 \mathrm{~b}$ is a simple expression of the importance of scintigraphy test in our studied population. In particular we noticed that: 10 patients (27\%) had a negative ECG but positive scintigraphy, 17 (46\%) had both a negative ECG and scintigraphy, 4 patients $(11 \%)$ had a positive ECG but negative scintigraphy, and $6(16 \%)$ had a positive ECG and scintigraphy.

These results are very important because they emphasize some of the statistical parameters that are useful in helping to understand the real importance of our instrumental tools. We can notice that we have reached a good degree of specificity of the test (81\%) with a positive and negative predictive value of $60 \%$ and $63 \%$, respectively.

In the end, we can underline that the results showed an important association between significant carotid stenosis and a positive stress test.

Table 4 shows that, among the 16 patients with positive scintigraphy findings, all had at least 1 risk factor: 8 patients (50\%) had 1 risk factor, 4 ( $25 \%$ ) had 2 risk factors, $3(18.75 \%)$ had 3 risk factors, and $1(6.25 \%)$ had 4 risk factors. Among the 21 patients with negative scintigraphy: 1 patient ( $4.76 \%$ ) had no risk factors, $3(14.29 \%)$ had 1 risk factor, $10(47.62 \%)$ had 2 risk factors, $6(28.75 \%)$ had 3 risk factors, and 1 ( $4.76 \%)$ had 4 risk factors.

\section{Discussion}

SMI is a documented ischemia in the absence of chest discomfort or other anginal equivalents. It is the most common manifestation of CHD. ${ }^{5}$

About $40 \%$ of patients with CHD have acute episodes of myocardial ischemia during daily life; $75 \%$ of these episodes are asymptomatic and considered silent (SMI).${ }^{15}$ Consciousness of the incidence of SMI in high-risk populations can reduce cardiovascular events and death rates.

In the Framingham Study, about $24 \%$ of the patients who suffered from heart attack had unrecognized episodes. ${ }^{16}$ Half of these episodes were silent, and the other half were atypical (events accompanied by some symptoms that neither physician nor patient recognize as manifestations of a heart attack).

The precise mechanism for pathogenesis and pathophysiology of SMI remains to be clarified. Beta-adrenergic

Table 3a Correlations between simple scintigraphy and exercise test

\begin{tabular}{llll}
\hline Exercise test & \multicolumn{2}{l}{ Scintigraphy } & Total \\
\cline { 2 - 3 } & Negative & Positive & \\
\hline Negative & 17 & 10 & 27 \\
Positive & 4 & 6 & 10 \\
Totals & 21 & 16 & 37 \\
\hline
\end{tabular}

Table 3b Evaluation of scintigraphy test in our population

\begin{tabular}{ll}
\hline & $\begin{array}{l}\text { Estimated value (95\% } \\
\text { confidence interval) }\end{array}$ \\
\hline Prevalence (\%) & $43(28-60)$ \\
Sensitivity (\%) & $38(16-64)$ \\
Specificity (\%) & $81(57-94)$ \\
Positive predictive value (\%) & $60(27-86)$ \\
Negative predictive value (\%) & $63(42-80)$ \\
\hline
\end{tabular}

receptors, adenylyl cyclase, and guanine nucleotide binding proteins ( $\mathrm{G}$ proteins) are considered to have an important role in the myocardial ischemic process of SMI. ${ }^{17}$

SMI happens when myocardial ischemia causes ECG changes but fails to reach the pain threshold, or when ischemia is less severe and of shorter duration than symptomatic ischemia. ${ }^{18}$ Some patients may not perceive chest pain during myocardial ischemia because they have a high pain threshold, or possibly because they have a defective perception of painful stimuli. ${ }^{19,20}$ In diabetes patients, it is suspected that partial or complete autonomic denervation may contribute to the prevalence of silent ischemia. ${ }^{21,22}$

SMI is associated with a circadian pattern, and many events occur in the morning. This may be because of elevated heart rate and blood pressure, higher catecholamine concentrations, increased coronary vasomotor tone, greater platelet aggregation response, and a reduced intrinsic fibrinolytic process.

Diabetes, hypertension, previous MI, surgical revascularization, and advanced age are all presumed risk factors for silent ischemia, ${ }^{23}$ even though many affected individuals do not have any apparent risk factors and seem to be totally asymptomatic.

The detection of patients affected by SMI is an ambitious project but difficult to perform in a general population. It could be useful in patients with epi-aortic stenotic vessel lesions, in whom there is a high prevalence of coronary disease. Schoenenberger et $\mathrm{al}^{24}$ tried to solve the problem in their study. They considered 54 patients with SMI out of the Swiss Interventional Study on Silent Ischemia Type I (SWISSI I) study. ${ }^{25}$ In this case SMI was assessed by bicycle ergometry

Table 4 Population risk factors and scintigraphy results

\begin{tabular}{lll}
\hline Risk factors (no.) & \multicolumn{2}{l}{ Scintigraphy } \\
\cline { 2 - 3 } & Negative & Positive \\
\hline $0(\%)$ & $\mathrm{I}(4.76)$ & $0(0)$ \\
$\mathrm{I}(\%)$ & $3(14.29)$ & $8(50)$ \\
$2(\%)$ & $10(47.62)$ & $4(25)$ \\
$3(\%)$ & $6(28.75)$ & $3(18.75)$ \\
$4(\%)$ & $\mathrm{I}(4.76)$ & $\mathrm{I}(6.25)$ \\
Totals & $21(56.75)$ & $16(43.25)$ \\
\hline
\end{tabular}


and stress imaging (echocardiography or scintigraphy). In this way they found a high incidence of relevant CAD among totally asymptomatic patients with myocardial ischemia during stress testing. They reported that previously healthy subjects with exercise-induced ST-segment depression at check-up examinations, even if asymptomatic, should have further diagnostic evaluation. Similar findings come from Schoenenberger et al, ${ }^{26}$ who evaluated the occurrence of sudden cardiac death (SCD) in patients with silent ischemia after MI coming from the SWISSI II. Patients (201) with silent ischemia after MI were randomized to percutaneous coronary intervention (PCI) or medical management. The main end point of their analysis was SCD. Patients with silent ischemia after MI undergoing PCI had better longterm left ventricular ejection fraction and a reduced SCD incidence. But a PCI procedure in patients with SMI seems unnecessarily aggressive. Nuclear imaging seems to be the answer to this problem. Zellweger et al, ${ }^{27}$ who analyzed 3664 asymptomatic patients "without" CAD history undergoing SPECT, observed that $\geq 7.5 \%$ ischemic myocardium was related to high risk factors. Scholte et $\mathrm{al}^{28}$ had earlier reported the importance of imaging nuclear techniques in evaluation of SMI in individuals with type 2 diabetes. Several studies have shown that SMI is predictive of increased cardiac risk in diabetic and elderly patients. ${ }^{19,29,30}$

The results of our study seem to be an intellectual paradox: scintigraphy seems to be positive in patients with SMI and a low degree of carotid IMT $(35 \% \pm 7 \%)$, and negative in patients with SMI and moderate degree of carotid IMT (44\% $\pm 13 \%$ ) (significant, $P=0.023$ ). This result could be due to the small sample analyzed or, more likely, other conditions that could not be identified by nuclear imaging could have influenced the results. In particular we speculate about carotid plaque characteristics such as its morphology and inner constitutions. These peculiarities could be related to ischemic disorders. In fact, a small plaque, perhaps eccentric or in a condition of inner inflammation, could be considered even worse than a larger one calcified or stable. ${ }^{31,32}$ It could be possible that a younger peripheral plaque, not well established in the arterial wall and not overcome by the development of collateral series of vessels, could become more dangerous than a well-established one. This latest one, named "stable plaque" cause of a calcification process and unable to induce a really hemodynamical impairment thanking the collateral pathways, would go to a rupture process less frequently than a younger one. For this reason patients with stable plaques would have a number of positive stress tests inferior than the ones with younger plaques. However, more studies on such an argument are needed in the near future in order to clarify our data and the values coming from our research.

In clinical practice it is difficult to identify subjects with a high risk of SMI among an asymptomatic population. The rationale for identifying patients with SMI is that this disorder is associated with an increase in coronary risk.

All patients with carotid plaques and cerebrovascular disease who are eligible for the exercise stress test should undergo stress test screening for the risk of heart attack. Patients who are not candidates for the stress test may undergo dipyridamole scintigraphy or echocardiography. ${ }^{33}$

Our results showed that the prevalence of SMI in a population affected by silent obstructive carotid artery disease was high, no less than $43 \%$. Other published studies have reported an SMI prevalence ranging from $23 \%$ to $40 \% .^{34,35}$ These differences are likely due to the different techniques used and the variability of the studied population. A specificity of $81 \%$ was reached in our population but the small sample could influence such a result.

The high prevalence of SMI in our selected population with suspected coronary disease further stresses the importance of this screening, both for improving quality of life and extending survival.

\section{Study limitations}

The small sample we evaluated could represent a limitation of our study. Nevertheless, our findings could help to improve our understanding of the relationship between heart and peripheral artery function in myocardial ischemia. Further investigation is needed in order to improve research in this field.

\section{Conclusion}

This study suggests a correlation between carotid and coronary atherosclerosis, but the result of most interest is the apparent paradoxical finding of a positive scintigraphy test with a lower degree of stenosis. This result highlights the need for further analysis in order to determine the importance of plaque morphology in cardiovascular risk stratification of a patient with SMI.

\section{Acknowledgment}

We would like to thank MV Pragnell, BA, for English text revision.

\section{Disclosure}

The authors report no conflicts of interest in this work. 


\section{References}

1. Deedwania PC, Carbajal EV. Silent myocardial ischemia-A clinical perspective. Arch Intern Med. 1991 Dec;151(12):2373-2382.

2. Kaski JC, Sales Cosin J, Arroyo Espliguero R. Silent myocardial ischaemia: clinical relevance and treatment. Expert Opin Investig Drugs. 2005 Apr;14(4):423-434.

3. Gottlieb SO, Gotlieb SH, Achuff SC, et al. Silent ischemia on Holter monitoring predicts mortality in high-risk postinfarction patients. JAMA. 1988 Feb 19;259(7):1030-1035.

4. Deedwania P, Carbajal E. Prevalence and patterns of silent myocardial ischemia during daily life in stable angina patients receiving conventional antianginal drug therapy. Am J Cardiol.

5. Cohn PF, Fox KM. Silent myocardial ischemia. Circulation. 2003;108; 1263-1277.

6. Pepine C, Hill J, Imperi G. Beta-adrenergic blocker in silent myocardial ischemia. Am J Cardiol. 1988 Jan 29;61(3):18B-21B.

7. Multiple Risk Factor Intervention Trial Research Group: Exercise electrocardiogram and coronary heart disease mortality in the M.R.F.I.T. Am J Cardiol. 1985 Jan 1;55(1):16-24.

8. Rautaharju PM, Prineas RJ, Eifler WJ, et al. Prognostic value of exercise electrocardiogram in men at high risk of future coronary heart disease: Multiple Risk Factor Intervention Trial experience. J Am Coll Cardiol. 1986;8:1-10.

9. Mostaza JM, González-Juanatey JR, Castillo J, Lahoz C, FernándezVillaverde JM, Maestro-Saavedra FJ. Prevalence of carotid stenosis and silent myocardial ischemia in asymptomatic subjects with a low ankle-brachial index. J Vasc Surg. 2009;49:104-108.

10. Duval M, Altman JJ. When should ultrasonography be used to detect asymptomatic carotid atheroma in diabetic patients? Diabetes Metab. 2006;32:638-642.

11. Agarwal AK, Gupta PK, Singla S, Garg U, Prasad A, Yadav R. Carotid intimomedial thickness in type 2 diabetic patients and its correlation with coronary risk factors. J Assoc Physicians India. 2008;56:581-586.

12. Urbinati S, Di Pasquale G, Andreoli A, et al. Frequency and prognostic significance of silent coronary artery disease in patients with cerebral ischemia undergoing carotid endarterectomy. Am J Cardiol. 1992 May 1; 69(14):1166-1170.

13. National Cholesterol Education Program (NCEP) Expert Panel on Detection, Evaluation, and Treatment of High Blood Cholesterol in Adults (Adult Treatment Panel III). Third Report of the National Cholesterol Education Program (NCEP) Expert Panel on Detection, Evaluation, and Treatment of High Blood Cholesterol in Adults (Adult Treatment Panel III) final report. Circulation. 2002;106:3143-421.

14. Touboul PJ, Hennerici MG, Meairs S, et al. Mannheim carotid intimamedia thickness consensus (2004-2006). An update on behalf of the Advisory Board of the 3rd and 4th Watching the Risk Symposium, 13th and 15th European Stroke Conferences, Mannheim, Germany, 2004, and Brussels, Belgium, 2006. Cerebrovasc Dis. 2007;23:75-80.

15. Solomon H, DeBusk RF. Contemporary management of silent ischemia: the role of ambulatory monitoring. Int J Cardiol. 2004;96:311-319.

16. Boland LL, Folsom AR, Sorlie PD, et al. Occurrence of unrecognized myocardial infarction in subjects aged 45 to 65 years (the ARIC study). Am J Cardiol. 2002;90:927-931.

17. Gutterman DD. Silent myocardial ischemia. Circ J. 2009;73:785-797.

18. Ahmed AH, Shankar KJ, Eftekhari H, et al. Silent myocardial ischemia: current perspectives and future directions. Exp Clin Cardiol. 2007 Winter;12(4):189-196.

Vascular Health and Risk Management

\section{Publish your work in this journal}

Vascular Health and Risk Management is an international, peerreviewed journal of therapeutics and risk management, focusing on concise rapid reporting of clinical studies on the processes involved in the maintenance of vascular health; the monitoring, prevention and treatment of vascular disease and its sequelae; and the involvement of
19. Deedwania PC. Silent myocardial ischemia in the elderly. Drugs Aging. 2000;16:381-389.

20. Masaki I, Keiichi F. New aspects for the treatment of cardiac diseases based on the diversity of functional controls on cardiac muscles: the regulatory mechanisms of cardiac innervation and their critical roles in cardiac performance. J Pharmacol Sci. 2009;109:348-353.

21. Hsieh MC, Tien KJ, Chang SJ, et al. High-sensitivity C-reactive protein and silent myocardial ischemia in Chinese with type 2 diabetes mellitus. Metabolism. 2008;57:1533-1538.

22. Barthelemy $\mathrm{O}$, Jacqueminet $\mathrm{S}$, Rouzet $\mathrm{F}$, et al. Intensive cardiovascular risk factors therapy and prevalence of silent myocardial ischaemia in patients with type 2 diabetes. Arch Cardiovasc Dis. 2008;101:539-546.

23. D'Antono B, Dupuis G, Arsenault A, Burelle D. Silent ischemia: silent after all? Can J Cardiol. 2008 Apr;24(4):285-291.

24. Schoenenberger AW, Jamshidi P, Zuber M, Stuck AE, Pfisterer M, Erne P. Coronary artery disease is common in asymptomatic patients with signs of myocardial ischemia. Eur J Intern Med. 2009;20:607-610.

25. Erne P, Schoenenberger AW, Zuber M, et al. Effects of anti-ischaemic drug therapy in silent myocardial ischaemia type I: the Swiss Interventional Study on Silent Ischaemia type I (SWISSI I): a randomized, controlled pilot study. Eur Heart J. 2007;28:2110-2117.

26. Schoenenberger AW, Kobza R, Jamshidi P, et al. Sudden cardiac death in patients with silent myocardial ischemia after myocardial infarction (from the Swiss Interventional Study on Silent Ischemia Type II [SWISSI II]). Am J Cardiol. 2009;104:158-163.

27. Zellweger MJ, Hachamovitch R, Kang X, et al. Threshold, incidence, and predictors of prognostically high-risk silent ischemia in asymptomatic patients without prior diagnosis of coronary artery disease. $J \mathrm{Nucl}$ Cardiol. 2009;16:193-200.

28. Scholte AJ, Schuijf JD, Kharagjitsingh AV, et al. Different manifestations of coronary artery disease by stress SPECT myocardial perfusion imaging, coronary calcium scoring, and multislice CT coronary angiography in asymptomatic patients with type 2 diabetes mellitus. J Nucl Cardiol. 2008;15:503-509.

29. Vanzetto G, Halimi S, Hammoud T, et al. Prediction of cardiovascular events in clinically selected high-risk NIDDM patients: prognostic value of exercise stress test and thallium-201 single-photon emission computed tomography. Diabetes Care. 1999;22:19-26.

30. Cosson E, Paycha F, Pariès J, et al. Detecting silent coronary stenoses and stratifying cardiac risk in patients with diabetes: ECG stress test or exercise myocardial scintigraphy? Diabet Med. 2004;21:342-348.

31. Rerkasem K, Gallagher PJ, Grimble RF, Calder PC, Shearman CP. Managing hypercholesterolemia and its correlation with carotid plaque morphology in patients undergoing carotid endarterectomy. Vasc Health Risk Manag. 2008;14:1259-1264.

32. Rennenberg RJMW, Kessels AGH, Schurgers LJ, van Engelshoven JMA, de Leeuw PW, Kroon AA. Vascular calcifi cations as a marker of increased cardiovascular risk: A meta-analysis. Vasc Health Risk Manag. 2009;5:185-197.

33. Sharma R, Pellerin D. Stress echocardiogaphy: A useful test for assessing cardiac risk in diabetes. Vasc Health Risk Manag. 2009;5:1-7.

34. Fleg JL. Prevalence and prognostic significance of exercise-induced silent myocardial ischemia in apparently healthy subjects. Am J Cardiol. 1992;69:14B-18B.

35. Katzel LI, Sorkin JD, Goldberg AP. Exercise-induced silent myocardial ischemia and future cardiac events in healthy, sedentary, middle-aged and older men. J Am Geriatr Soc. 1999;47:923-929.

\section{Dovepress}

metabolic disorders, particularly diabetes. This journal is indexed on PubMed Central and MedLine. The manuscript management system is completely online and includes a very quick and fair peer-review system, which is all easy to use. Visit http://www.dovepress.com/ testimonials.php to read real quotes from published authors. 